\title{
Законодательное регулирование избирательных правоотношений в субрегионе \\ Центральной Америки
}

Крупышев Д.А. *

Характерная особенность избирательного законодательства государств субрегиона Центральной Америки - включение норм, регулирующих правоотношения, возникающие в связи с нарушением установленного законом порядка проведения выборов, непосредственно в текст избирательных законов и кодексов, что объясняется как спецификой исторического развития центральноамериканских государств, так и усилившейся в последнее десятилетие $\mathrm{XX}$ века тенденцией к унификации национальных избирательных законодательств. В настоящее время лишь избирательное законодательство Сальвадора наряду с нормами, особо регулируюшими соответствуюшие правоотношения, имеет также специальные отсылочные нормы к общему административному и уголовному законодательству.

В регулировании правоотношений, возникающих в связи с нарушением установленного законом порядка проведения выборов, в государствах Центральной Америки можно выделить две преобладающие тенденции.

Первая из них характерна только для избирательного законодательства Гватемалы. В этом государстве законодатель лишь в самых общих чертах регулирует правоотношения, возникающие в связи с нарушением установленного законом порядка проведения выборов. В законе определены понятия избирательное преступление и избирательное правонарушение, установлена различная степень ответственности за каждый вид правонарушения. Однако в законе отсутствуют перечень избирательных правонарушений, а также условия привлечения к ответственности виновных и конкретные санкции.

По законодательству Гватемалы избирательным преступлением считается виновное деяние (действие или бездействие), совершенное с целью воспрепятствовать нормальному ходу избирательного процесса, сделать невозможным или затруднить проведение голосования, изменить результаты выборов. За его совершение установле-

* Крупышев Дмитрий Анатольевич, аспирант кафедры Конституционного права МГИМО (Университета) МИД России 
на санкция: лишение свободы на срок от шести месяцев до шести лет. Избирательное правонарушение закон определяет как менее сушественное нарушение избирательного законодательства, не являющееся избирательным преступлением. Избирательное правонарушение наказывается арестом на срок от 10 до 60 дней $^{1}$.

Вторая тенденция сформировалась в Белизе, Гондурасе, Коста-Рике, Никарагуа, Панаме и Сальвадоре. Специфическая особенность избирательного законодательства этих стран состоит в очень подробной регламентации избирательным законом комплекса правоотношений, возникаюших в результате нарушения законодательства о выборах.

Избирательные законы содержат специальные разделы, в которых перечислены составы и существенные признаки конкретных правонарушений, совершаемых на каждой стадии избирательного процесса, указывается круг лиц, подлежащих ответственности за их совершение, а также устанавливаются основные и дополнительные санкции за их совершение. Ниже дается краткий обзор основных правонарушений, совершаемых на различных стадиях избирательного процесса, проводится сравнительно-правовой анализ регулирования соответствующих правоотношений.

В ходе выборов нанболее серьезными признаются правонарушения против установленного порядка формирования и деятельности государственных избирательных органов. Степень общественной опасности таких правонарушений весьма высока, поскольку они могут обусловить признание выборов недействительными. Этим объясняются жесткие санкции за данные правонарушения во всех вышеназванных странах. В большинстве из них наиболее жесткие санкции установлены за правонарушения данной группы, совершенные должностными лицами, но в некоторых странах они действуют также и в отношении частных лиц.

Наиболее распространенное должностное правонарушение на данной стадии избирательного процесса - нарушение установленного порядка формирования и деятельности территориальных избирательных органов. За совершение данного правонарушения установлены наиболее жесткие санкции - лишение свободы на срок от 2 до 8 лет (Коста-Рика). За совершение данного правонарушения ответственности подлежат должностные лица вышестоящих избирательных органов. К этой же категории относятся менее тяжкие правона-

1 ! : Hectoral ! Je Partidos Politicos de la Republica de Guatemala 1986. Arto. 255. 
рушения - отказ от исполнения обязанностей члена комиссии по сбору голосов без уважительной причины (Никарагуа), его неявка в назначенное время для исполнения своих обязанностей (Панама).

Общественная опасность данных правонарушений в значительной степени ниже из-за наличия в избирательном праве государств субрегиона института суплента (заместителя должностного лица), который незамедлительно приступает к исполнению обязанностей отсутствующего штатного должностного лица. Меньшей общественной опасностью объясняются и более мягкие санкции за совершение относящихся к данной категории правонарушений (например, в Панаме виновное лицо подвергается аресту сроком на 24 часа).

Специфический состав относимого к данной категории правонарушения известен избирательному законодательству Сальвадора, предусматривающему штраф в сумме от 1000 до 10000 колонов за непредставление кандидатур для включения в состав территориальных избирательных комиссий лицами, обязанными по закону это делать (высшие должностные лица органов государственной власти, ректоры университетов, руководители профессиональных союзов и ассоциаций частных предприятий).

Как свидетельствует практика, частные лица чаще всего совершают правонарушения против установленного порядка формирования и деятельности государственных избирательных органов в форме несоблюдения законных распоряжений и предписаний избирательного органа. Ответственность за его совершение содержится в избирательном законодательстве всех рассматриваемых государств. Наиболее жесткие санкции установлены в Гондурасе - лишение свободы на срок до 6 лет с наложением запрета состоять на государственной службе в течение 1 года после истечения срока основного наказания.

Следующая категория правонарушений - правонарушения против установленного порядка регистрации избирателей. Высокая степень их общественной опасности объясняется лишением граждан возможности реализовать свое право на участие в выборах. Так же, как и правонарушения против порядка формирования и деятельности избирательных органов, этот вид правонарушений подразделяется на должностные правонарушения и правонарушения, совершаемые частными лицами.

В качестве примера должностных правонарушений, относяшихся к данной категории, можно назвать необоснованный отказ в регистрации в качестве избирателя в избирательном реестре, двойную ре- 
гистрацию в качестве избирателя, а также регистрацию в качестве избирателя лица, не имеющего права на участие в выборах. Ответственность за перечисленные правонарушения предусмотрена законодательством всех названных государств. Наиболее строга она в Коста-Рике (лишение свободы на срок от 2 до 8 лет).

Наиболее строгое наказание по совокупности основного и дополнительного видов наказания налагается на правонарушителя в Белизе. Основное наказание предусматривает штраф размером 1000 долларов и арест на срок до 1 года или без такового. Помимо основного, правонарушителю назначаются следующие дополнительные наказания: лишение права получить жалованье за год, а также быть избранным депутатом Национальной Ассамблеи в течение 7 лет и, наконец, лишение активного избирательного права на тот же срок.

Говоря о должностных правонарушениях против установленного порядка регистрации избирателей, отметим, что ответственности за них подлежат не только сотрудники избирательных органов, но и иные государственные служащие и даже частные лица, на которых закон возлагает отдельные публичные обязанности. К примеру, подобным правонарушением признается отказ нотариуса от свидетельствования юридических фактов в ходе проведения избирательных мероприятий. В Гондурасе, например, это правонарушение наказывается штрафом в сумме 50 лемпир.

С.едуюшая категория правонарушений - нарушение установленно1о порядка выдвижения кандидатов на публичные должности.

Их обшественная опасность заключается в нарушении установленного конституцией права граждан быть избранными на публичные должности. Примером таких правонарушений можно назвать воспрепятствование выдвижению гражданином своей кандидатуры на выбоpax (Панама), включение гражданина в список кандидатов без его согласия (Гондурас), принуждение его поставить свою подпись в подписном листе в поддержку определенного кандидата (Никарагуа), дача (получение) взятки за выдвижение либо снятие своей кандндатуры на выборах, а равно посредничество в ее даче (Панама, Белиз).

Санкции, установленные за совершение данных правонарушений, как правило, предусматривают либо крупный штраф (до 50000 бальбоа в Панаме), либо лишение свободы на срок до 1 года. За дачу взятки санкции гораздо строже. В Панаме правонарушитель наказывается лишением свободы на срок до 3 лет. В Белизе основное наказание хотя и менее строгое (штраф в размере 500 долларов с лише- 
нием свободы на срок до 1 года или без такового), однако если нарушителем признано должностное лицо, предусмотрено дополнительное наказание в виде лишения права быть избранным депутатом Национальной Ассамблеи в течение 7 лет и одновременно лишением активного избирательного права на тот же срок.

Помимо перечисленных составов правонарушений, законодательство отдельных государств устанавливает специальные санкции за правонарушения, связанные с порядком деятельности политических партий и их членов в процессе выдвижения и регистрации кандидатов на выборные должности. Такие нормы содержатся, в частности, в избирательном законодательстве Панамы. Так, известны два состава правонарушения, причем в первом случае к ответственности привлекаются руководители политической партии, во втором - ее рядовые члены.

К первому виду относится фальсификация регистрационных данных или документов политической партии. За совершение данного правонарушения к руководителям или законным представителям политической партии применяются санкции в виде лишения свободы на срок от 2 месяцев до 3 лет. Второй состав правонарушений образует умышленная подача на данных выборах гражданином, зарегистрированным в качестве члена какой-либо политической партии, заявления о вторичной регистрачии в качестве члена этой или любой другой политической партии, без прекращения членства в первой. Санкция за совершение данното правонарушения - штраф в сумме от 50 до 500 бальбоа ${ }^{2}$.

Во всех странах Центральной Америки наиболее подробно разработаны нормы, касающиеся правонарушений против установленного порядка ведения предвыборной агитации. Это обусловлено тем, что проводимые в рамках предвыборной агитации мероприятия, предоставляют их организаторам наибольшие возможности по воздействию на обшественное мнение. Нарушение установленного порядка проведения мероприятий влечет наибольшее противоправное воздействие на охраняемые законом права и интересы граждан.

Правонарушения против установленного порядка ведения предвыборной агитации также подразделяются на должностные и на правонарушения, совершаемые частными лицами.

В ходе избирательной кампании наиболее распространено злоупотребление должностным положением, например, путем принуж-

2 Codigo Electoral de la Republica de Panama de 1988. Arto. 325. 
дения подчиненных лиц к участию в предвыборных мероприятиях в поддержку какого-либо кандидата (Белиз, Коста-Рика, Панама). Наиболее строгое наказание за совершение этого правонарушения установлено в Панаме - в виде лишения свободы на срок от 2 месяцев до 3 лет. Кроме того, должностным правонарушением признается проведение агитации в государственных учреждениях, либо использование государственного имущества для предвыборной агитации (Панама, Гондурас, Коста-Рика, Сальвадор, Никарагуа). Это правонарушение наказывается штрафом во всех государствах, кроме Никарагуа, где оно влечет наказание в виде лишения свободы на срок от 1 года до 2 лет.

Законодательство большинства стран устанавливает ответственность за нарушение запретов и ограничений при проведении предвыборной агитации. Так, законодательство Сальвадора предусмотрело ответственность за нарушение государственными и муниципальными служашими запрета на публикацию в СМИ менее чем $3 а 30$ дней до даты выборов любых отчетов о деятельности правительства, иных государственных органов, а также о введенных в строй объектах и заключенных контрактах, финансируемых за счет бюджета.

Ответственности за данное правонарушение подлежат должностные лица, представившие в средства массовой информации соответствующие материалы. Виновные в совершении данного правонарушения должностные лица наказываются штрафом в размере от 1000 до 10000 колонов. При этом руководитель издания, санкционировавший публикацию таких материалов, может быть отстранен от должности по решению высшего избирательного органа (оно принимается не позднее, чем через 72 часа после выхода в свет публикации).

Следует отметить, что предусмотренная законодательством Сальвадора ответственность средства массовой информации за нарушение установленного законом запрета - наименьшая среди государств Центральной Америки. Наиболее строгая ответственность установлена в Гондурасе: за первое нарушение на СМИ налагается штраф в сумме от 5000 до 10000 лемпир, за второе - сумма штрафа удваивается, третье нарушение влечет запрет деятельности СМИ сроком на 3 месяца, за четвертое оно закрывается ${ }^{3}$.

Типичным правонарушением, совершаемым частными лицами в ходе избирательной кампании, признается предвыборная агитация

${ }^{3}$ Ley Electoral y de las Organizaciones Politicas de la Republica de Honduras 1981. Arto. 74. 
после истечения установленного законом срока (Никарагуа, Сальвадор), пропаганда избирательного абсентеизма (Гондурас, Никарагуа), распространение ложных сведений о кандидате, в том числе персонального характера (Белиз).

Наиболее строгое наказание установлено за пропаганду избирательного абсентеизма - лишение свободы на срок от 6 до 8 лет (Гондурас). При этом наряду с основным назначается и дополнительное наказание - запрет состоять на государственной службе в течение 1 года после отбытия основного наказания. Столь строгое наказание объясняется тем, что в каждом из перечисленных государств закон устанавливает обязанность избирателя участвовать в голосовании. Поэтому пропаганда избирательного абсентеизма рассматривается как тяжкое уголовное правонарушение и влечет наказание в виде лишения свободы на длительный срок. За совершение иных правонарушений ответственность, как правило, менее строгая - денежный штраф (в Сальвадоре, например, он составляет от 10000 до 50000 колонов), либо лишение свободы на срок до года.

Существует отдельная группа финансовых правонарушений. К ним относится незаконное получение и использование денежных средств и материальных ценностей для ведения избирательной кампании, а также нецелевое использование бюджетных ассигнований. Ответственность за совершение указанных правонарушений предусмотрена законодательством всех рассматриваемых государств. В большинстве из них ответственность установлена за совершение такого правонарушения только в отношении руководителей и уполномоченных финансовых представителей политических партий, а также кандидатов, получающих или использующих финансовые средства и иные активы с нарушением установленного законом порядка.

Специфическую особенность избирательного законодательства Гондураса составляет как более широкий состав финансовых избирательных правонарушений, так и более широкий круг лиц, подлежащих ответственности за их совершение. Финансовые избирательные правонарушения, предусмотренные избирательным законодательством Гондураса, подразделяются на две группы.

К первой группе относятся правонарушения, касающиеся противоправного получения и использования средств на избирательные цели: получение финансирования от государственных и муниципальных органов (кроме предусмотренных законом бюджетных ассигнований), государственных и муниципальных предприятий, ано- 
нимных пожертвований (кроме пожертвований, собранных путем добровольного сбора средств граждан), пожертвований от иностранных юридических лиц и граждан.

Вторая группа правонарушений связана с организацией и осуществлением незаконного финансирования политических партий и кандидатов. К этим правонарушениям, помимо незаконного использования государственного имущества для ведения избирательной кампании, о котором упоминалось выше, относится также организация сбора средств в поддержку какой-либо политической партии или кандидата руководителями государственных органов и предприятий среди подчиненных им служащих, а также принуждение работников к сбору средств в поддержку какой-либо политической партии или кандидата.

Санкции за эти правонарушения применяются как к лицам, организующим или осуществляющим незаконное предвыборное финансирование, так и к руководителям, финансовым уполномоченным, кандидатам от политических партий, получающих такое незаконное финансирование. За совершение этих правонарушений установлена ответственность: основная (штраф в размере 200\% незаконно перечисленных или полученных сумм) и дополнительная (приостановление действия активного и пассивного избирательного права правонарушителя на срок от 2 до 3 лет с одновременным запретом состоять на государственной службе на тот же срок) $)^{4}$.

Особое место в избирательном законодательстве государств Центральной Америки отводится нормам, устанавливающим ответственность за правонарушения, совершенные на стадии голосования, что обусловлено крайне высокой общественной опасностью этих правонарушений, непосредственно затрагивающих конституционные избирательные права граждан. Наиболее широк субъектный состав этих правонарушений. При этом особо выделяются несколько категорий правонарушений: должностные правонарушения сотрудников избирательных органов, военнослужащих и служащих полиция; правонарушения, совершенные иностранными гражданами, а также избирателями. Ниже дается краткий обзор и сравнительный анализ соответствующих норм правового регулирования.

Наибольшее количество содержащихся в избирательных законах норм, касающихся правонарушений против установленного порядка

${ }^{4}$ Ley Electoral y de las Organizaciones Politicas de la Republica de Honduras 1981. Arto. 243. 
голосования, приходится на должностные правонарушения членов избирательных органов. Вот типичные правонарушения:

- умышленное изъятие, задержание, приведение в негодность избирательных документов у одного или нескольких избирателей или избирательных бюллетеней и урн для голосования. Данные составы правонарушений предусмотрены избирательным законодательством Белиза, Гондураса и Коста-Рики. Наиболее жесткие санкции за совершение этих правонарушений установлены в Гондурасе: лишение свободы на срок от 6 до 8 лет с наложением запрета состоять на государственной службе в течение 1 года после отбытия основного наказания. Наиболее мягкое наказание предусмотрено законодательством Коста-Рики - арест от 25 до 180 дней, который может быть заменен штрафом в сумме от 50 до 360 колонов;

- необоснованный отказ выдать избирателю необходимые для голосования документы, а равно отказ от подписания и проставления печати на избирательных бюллетенях при их выдаче избирателям для голосования. Указанные составы правонарушений предусмотрены законодательством Коста-Рики и Гондураса. Установленное наказание аналогично описанному выше;

- - умышленное введение избирателей в заблуждение относительно содержания и способа заполнения избирательных бюллетеней, а равно распространение иной не соответствующей действительности информации, с целью обманным путем воспрепятствовать свободной реализации активного избирательного права граждан. Ответственность за совершение данного правонарушения предусмотрена законодательством Гондураса в виде лишения свободы на срок от 6 до 8 лет, а таюже запрета состоять на государственной службе в течение 1 года после отбытия основного наказания.

Особую категорию составляют правонарушения, совершаемые на стадии голосования, военнослужащими и служащими полиции. Как подобное правонарушение квалифицируется необоснованный отказ командира воинского подразделения или полицейского формирования, на которого возложено обеспечение общественного порядка на избирательном участке, в оказании необходимого содействия избирательному органу для поддержания общественного порядка в ходе голосования. Ответственность за данное правонарушение предусмотрена избирательным законодательством Коста-Рики в виде ареста на срок от 25 до 180 дней, который может быть заменен штрафом на сумму от 50 до 360 колонов 5 . 
Кроме того, после совершения такого деяния офицер немедленно отстраняется от должности, а при наличии отягчающих обстоятельств - увольняется.

Специфической категорией правонарушений считаются правонарушения, совершенные иностранными гражданами. Во всех государствах избирательное законодательство устанавливает запрет на участие иностранных граждан в избирательном процессе, нарушение которого влечет применение к правонарушителю крайне жестких санкций. Состав правонарушения на стадии голосования образует как собственно участие иностранца в голосовании, так и любые его действия, затрудняющие исполнение государственными органами возложенных на них обязанностей в процессе голосования. Ответственность за указанные правонарушения установлена в избирательном законодательстве Гондураса, Никарагуа и Сальвадора. Наиболее жесткие санкции установлены в Гондурасе: нарушителю назначается наказание в виде лишения свободы на срок 10 лет, после чего он подлежит немедленной депортации.

Значительное количество правонарушений против установленного порядка голосования совершают сами избиратели. Среди данной категории нанболее типичными правонарушениями признаны неучастие в голосовании без уважительной причины (в большинстве испаноязычных стран Центральной Америки), незаконное участие в выборах (Белиз, Коста-Рика, Панама), отказ избирателя от проставления ему специальной отметки на руке, удостоверяющей факт участия в голосовании ${ }^{6}$.

Наиболее строгое наказание за незаконное участие в выборах предусмотрено в Панаме, где на правонарушителя налагается штраф в размере до 50000 бальбоа с одновременным лишением свободы на срок от 1 до 12 месяцев; в качестве дополнительного наказания ему запрещается состоять на государственной службе на срок от 1 до 2 лет после отбытия наказания. Друтие правонарушения считаются менее тяжкими, поэтому наказание за их совершение менее строгое - например, неучастие в голосовании без уважительной причины в Гондурасе наказывается незначительным штрафом в размере 20 лемпир.

5 Codigo Electoral de la Republica de Costa Rica 1952. Arto. 271.

6 В большинстве стран Центральной Америки обязательное ироставление такой отметки предусмотрено законом в качестве дополнительной гарантии чистоты выборов - Д.К. 
Помимо рассмотренных составов правонарушений, избирательному законодательству некоторых стран субрегиона известны также составы правонарушений, отражающие специфику правового регулирования процесса голосования в этих странах. В качестве примеров такого рода правонарушений можно привести следующие составы, предусмотренные избирательным законодательством Белиза и Коста-Рики:

- нарушение тайны голосования избирателем посредством публичной демонстрации заполненного избирательного бюллетеня. Данное правонарушение по законодательству Коста-Рики наказывается арестом на срок от 25 до 180 дней либо штрафом от 50 до 360 колонов;

- помещение в избирательную урну иных документов, нежели избирательные бюллетени, а равно извлечение из нее иных документов. Это правонарушение, установленное законодательством Белиза, наказывается штрафом в сумме 1000 долларов или лишением свободы на срок 3 года;

- нахождение на расстоянии ближе 100 ярдов от помещения избирательного участка. Данное правонарушение предусмотрено законодательством Белиза. Санкция за совершение данного правонарушения установлена в виде штрафа в размере 500 долларов с лишением свободы на срок до 6 месяцев или без такового.

К этой же категории избирательных правонарушений относятся несоблюдение гражданами норм общественной морали, за которое установлена особая ответственность. Такие правонарушения известны только избирательному законодательству Коста-Рики. Так, гражданин, явившийся на избирательный участок в состоянии опьянения, наказывается штрафом в сумме от 50 до 360 колонов или арестом на срок от 25 дней до 180 дней.

Необходимо отметить наличие в избирательном законодательстве некоторых стран Центральной Америки норм, устанавливающих ответственность за нарушение специальных законодательных запретов в день голосования. Так, избирательное законодательство ряда стран - Белиза, Гондураса, Коста-Рики и Панамы, установило ответственность за продажу спиртных напитков в день голосования, а также в день, предшествующий ему, и в день, следующий за голосованием. Во всех государствах данное правонарушение наказывается крупным денежным штрафом (500 долларов в Белизе, 1000 лемпир в Гондурасе и 100000 бальбоа в Панаме). В Гондурасе и Панаме, по- 
мимс уплаты штрафа, нарушитель лишается соответствующей специальной лицензии на продажу спиртных напитков на оставшуюся часть срока ее действия.

Последним из распространенных видов избирательных правонарушений признается нарушение установленного порядка определення результатов выборов. Большая часть таких правонарушений относится к категории должностных преступлений и наказывается лишением свободы. Наиболее типичное из данной категории правонарушение, - умышленная фальсификация итогов голосования посредством необоснованного завышения числа голосов, поданных в пользу какого-либо кандидата, за счет уменьшения их числа у другого кандидата. Наиболее суровое наказание за это правонарушение установлено избирательным законодательством Белиза - лишение свободы на срок 5 лет.

Важной составной частью регулирования правоотношений, возникаюших вследствие нарушения законодательства о выборах, являются процессуальные вопросы рассмотрения дел по соответствующим правонарушениям. Регулирование данных вопросов содержится в избирательном законодательстве всех стран Центральной Америки.

В большинстве стран Центральной Америки (Гватемала, Гондурас. Коста-Рика, Панама и Сальвадор) дела об избирательных правонарушениях рассматривают высшие избирательные органы.

Характерна процедура, установленная законодательством Панамы. В зтой стране производство по делу о совершенном правонарушения возбуждается высшим избирательным органом (Избирательным Трибуналом) по заявлению должностного лица нижестоящего 1 збирал ельного органа, о чем выносится письменное определение за поциисыо одного из магистров ${ }^{7}$, а копия направляется лицу, обвиняемому в совершении правонарушения. С момента предъявления обвинения обвиняемый имеет право на защиту. Защитника назначает Избирательный Трибунал из числа лиц, имеющих адвокатскую лицензию и аккредитованных при Суде второй инстанции Высшего Суда Справедливости либо при Избирательном Трибунале.

Как правило, следствие проводит непосредственно высший избиратенный орган, однако производство следственных действий по некоч рой категории дел составляет исключительную компетенцию спечильюоо управления Генеральной прокуратуры по избиратель-

? Млюин вьсанс должнос лино Избирательного Трнбунала. - Д.К. 
ным правонарушениям ${ }^{8}$. На их производство законом отводится пять дней, в течение которых обвиняемый может представлять любые доказательства в свою защиту. По окончании следственных действий проводится слушание и выносится решение, которое может быть обжаловано в апелляционном порядке ${ }^{9}$.

Специфика избирательного законодательства Никарагуа до 1996 года заключалась в том, что дела о правонарушениях в ходе избирательного процесса относились к компетенции судов по уголовным делам либо военных судов, в зависимости от конкретного состава правонарушения ${ }^{10}$. В настояшее время эта процедура не применяется. Действующее избирательное законодательство предусматривает создание специального Суда по избирательным делам компетентного рассматривать дела о совершенных в ходе избирательного процесса правонарушениях. Суд по избирательным делам создается не позднее 6 месяцев до выборов и функционирует до рассмотрения всех дел по состоявшимся выборам, после чего распускается. Производство по делу о совершенном избирательном правонарушении возбуждается Генеральной прокуратурой либо по письменному заявлению потерпевшего либо по собственной инициативе.

- В Белизе рассмотрение дел о правонарушениях, совершенных в ходе избирательного процесса, возложено на Председателя Верховного Суда, которому правомочного для рассмотрения конкретного дела назначать из состава судей Верховного Суда специального Избирательного судью, который в процессе пользуется теми же полномочиями, что и судья Верховного Суда. Дело слушается в открытом судебном заседании. Перед обязательным опросом свидетели приводятся к присяге. По итогам рассмотрения дела выносится решение, которое может быть обжаловано в апелляционном порядке.

Вынесенные и вступившие в силу решения обязательны для немедленного исполнения. Неисполнение вступившего в силу решения во всех государствах рассматривается как отдельный состав правонарушения и преследуется по закону. Специфика наказания, установ-

8 Такое требование установлено, в частности, в отношении расследования дел о нарушении общественного порядка на избирательном участке с применением оружия, дел о злоупотреблении правительственными чиновниками своими должностными полномочиями, а также дел, связанных с правонарушениями, совершенными должностными лицами избирательных органов - Д.К.

9 Codigo Electoral de la Republica de Panama de 1988. Arto. 485.

10 Ley Electoral de la Republica de Nicaragua 1988. Arto. 200. 
ленного решениями по делам об избирательных преступлениях, заключается в неприменении к осужденным амнистии и последующих законов, смягчающих санкции за аналогичные правонарушения.

Центральноамериканский законодательный опыт включения норм, устанавливающих ответственность за нарушение законодательства о выборах, непосредственно в избирательное законодательство заслуживает положительной оценки и нуждается в тщательном изучении. Думается, особого внимания российских законодателей заслуживают нормы, устанавливающие ответственность за использование продуктов "грязных" предвыборных технологий в ходе избирательной кампании. Не менее интересен для них опыт наделения полномочиями по рассмотрению дел о совершенных правонарушениях непосредственно высших избирательных органов, что позволяет государственным органам оказывать оперативное воздействие на ход выборов с целью пресечения нарушений закона. Наличие таких полномочий у избирательных органов - важная гарантия проведения выборов в установленном законом порядке, что особенно важно для стран, сравнительно недавно вступивших на путь демократического развития. 